\begin{tabular}{l} 
SCIENCE \& TECHNOLOGY \\
Journal homepage: http://www.pertanika.upm.edu.my/ \\
\hline PERTANIKA
\end{tabular}

\title{
Mathematical Modeling and Availability Analysis of Leaf Spring Manufacturing Plant
}

\author{
Sohan Lal Tyagi*, Shikha Bansal, Priyanka Agarwal and Ajay Singh Yadav \\ Department of Mathematics, SRM Institute of Science and Technology, Delhi-NCR Campus, \\ Modinagar, 201204, India
}

\begin{abstract}
In this manuscript, we portray the composition and availability analysis of leaf spring. In wheeled vehicles for the suspension, an elementary form of spring i.e. leaf spring is usually utilized. Particularly in industrial vehicles, Leaf springs are one of the widely recognized suspension segments they are frequently used. A method is presented that tests the availability of each part involved in the system as well as the system as a whole. Besides, the analysis demonstrates an optimization model that helps to boost the availability of the leaf spring production plant system. The system is divided into different subsystems considering various phases in the production of leaf spring. The framework of this system consists of four components i.e. shearing, punching, heating, and assembling. Using the Markov birth-death strategy we established the mathematical model of the plant. The matrix method is applied to simplify the differential equations and $\mathrm{C}$ programming survey the fluctuation of availability related to time. The numerical results for the different framework are given which are effective to enhance the maintenance policy of the system.
\end{abstract}

Keywords: Availability, failure rate, leaf spring, matrix method

ARTICLE INFO

Article history:

Received: 12 November 2020

Accepted: 25 February 2021

Published: 30 April 2021

DOI: https://doi.org/10.47836/pjst.29.2.18

E-mail addresses:

drsohantyagi@gmail.com (Sohan Lal Tyagi)

srbansal2008@gmail.com (Shikha Bansal)

priyanka1354@gmail.com (Priyanka Agarwal)

ajay29011984@gmail.com (Ajay Singh Yadav)

* Corresponding author

\section{INTRODUCTION}

The present organizations require the potential to tackle the latest proficiency that is accessible with the present innovation. In the era of competition among the manufacturing organizations, the appeal of quality production inside the expressed time span increases for assuring the requirement of patrons. The availability of production systems plays a significant role 
in accomplishing this necessity. The production system's availability can be improved by maximizing the efficiency of its sub-systems, which can be possible only through proper maintenance of the systems.

Kumar et al. (1989) used the probabilistic approach in the paper industry for the availability of the washing system. Singh and Mahajan (1999) examined the long-run availability and reliability of a utensils manufacturing plant. Garg et al. (2010) proposed a new technique in the plywood industry to find the reliability model of a block-board manufacturing system. Aggarwal et al. (2015) reported a mathematical model of the fertilizer plant of the urea synthesis system to find the mean time between failure and reliability analysis. Mangey and Manglik (2016) considered numerous aspects of failure and the reliability parameters of the dynamic repairable manufacturing system had been assessed.

In the field of reliability theory, mechanical systems have drawn the attention of researchers. Venkatesan and Devaraj (2012) defined a composite leaf spring concept and experimental study. Kumar and Reddy (2017) presented a finite element method to study the functionality of Leaf springs, design parameters that affected the suspension system on an automobile vehicle. So far, the leaf spring plant, which also plays an important role in our everyday lives, has not been addressed.

Jain et al. (2004) dealt with the degraded machine repair problem for the finite population Bernoulli feedback model. Yadav et al. (2008) developed a technique in the absence of data concerning failures. Agarwal and Bansal (2009) studied the head of line repair strategy to evaluate the reliability of a dynamic standby redundancy system with evolving environmental conditions. Shakuntala et al. (2011) applied a supplementary variable technique applied to compute the reliability of polytube manufacturing plant with variable rates of failure and repair. Mehta et al. (2017) emphasized on steel plant for High productivity. Kumar and Kadyan (2018) evaluated the profit and availability analysis of distillery plant through supplementary variable techniques. Bansal and Tyagi (2018) had applied the orthogonal matrix method to obtain reliability analysis of screw manufacturing plant. Gupta et al. (2019) introduced a neural network approach to predict different parameters of reliability. Jain et al. (2020) obtained the performance of redundant machining systems having imperfect fault detection and reboot delay.

Various techniques i.e., Runge-Kutta method, Laplace transform method, or Lagrange's method has been used to solve differential equations which include laborious estimations. Subsequently, it has been seen that in complex frameworks the computation of availability is extremely troublesome. So, we have built up the matrix method to illuminate differential equations and a computer program is created to ascertain the time-dependent availability. Table 1 to 7 for the estimation of time-dependent availability are prepared by $\mathrm{C}$ Programming. The findings of the analysis depict which subsystems and hardware 
are critical from an availability point of view. Hence, weak spots of the industry could be distinguished and maintained.

\section{MATERIAL AND METHODS}

In this paper, we consider a leaf spring manufacturing plant. The leaf spring plant consists of four components and detailed descriptions are as follows:

\section{Shearing Component}

In the leaf spring manufacturing plant, the shearing section is the most essential usual and inevitable tactics. For the cutting of the metal sheet, shearing is used normally to produce the primary workpiece, referred to as a blank, and for other sheet metal processes. It employs a single edge machine, the failure of which causes the leaf plant to fully fail.

\section{Punching Component}

For punching, the workpiece is set out in the appropriate orientation. To keep all the plates jointly a ditch at the center of each leaf is maintained. For this, a punching operation is carried out. It employs two units. This component can work in reduced capacity with one unit.

\section{Heating Component}

The heating component is achieved most effectively at the ends to be smooth to bend the ends. That is performed to fix the leaves to the frame of the vehicle. It consists of two units with minor and major failures.

\section{Assembly Component}

To check the quality examination and trial are carried out in the assembly component of the leaf springs. After inspection, the leaf springs with precise excellent and overall performance are allowed to stock storage. This component can work in reduced capacity with one unit.

\section{Assumptions}

(a) Originally all components are functioning.

(b) The rates of repair and failure are constant and statistically independent.

(c) Switch-over devices are perfect.

(d) Performance-wise, a repaired unit is in good condition as new.

(e) The capacity of the working units are similar to the standby units and are of the same nature 


\section{Notations}

$U, V, W, X:$ Good states condition of the leaf plant

$\bar{V}, \bar{X} \quad:$ Reduced capacity states

$u, v, w, x \quad$ :Represents the respective failed states of the system

$\eta_{i} \quad:$ Represents failure rates of $i^{\text {th }}$ unit of the system where $i=u, v_{1}, v_{2}, w, x_{1}, x_{2}$

$\gamma_{i} \quad:$ Represents repair, rates of $i^{\text {th }}$ unit of the system where $i=u, v_{1}, v_{2}, w, x_{1}, x_{2}$

$P_{i}(t) \quad$ : Probability of $i^{\text {th }}$ state at time $t$

$P_{i}(t) \quad$ : Rate of change of probability function $P_{i}(t)$

Av $(t) \quad:$ Availability of the system

The transition illustration of the leaf spring manufacturing plant is developed and shown in Figure1.



Figure 1. State transition illustration of leaf spring manufacturing plant

\section{Mathematical Modeling}

Using Markov birth-death process the following differential equations, correlated with the transition states are given by Figure 1.

$$
P_{0}^{\prime}(t)+\left(\eta_{u}+\eta_{w}+\eta_{x_{1}}+\eta_{v_{1}}\right) P_{0}(t)=\gamma_{u} P_{4}(t)+\gamma_{w} P_{5}(t)+\gamma_{v_{1}} P_{1}(t)+\gamma_{x_{1}} P_{2}(t)
$$




$$
\begin{gathered}
P_{1}^{\prime}(t)+\left(\eta_{u}+\eta_{w}+\eta_{x_{1}}+\eta_{v_{2}}+\gamma_{v_{1}}\right) P_{1}(t)=\gamma_{v_{2}} P_{7}(t)+\eta_{v_{1}} P_{0}(t)+\gamma_{u} P_{6}(t)+\gamma_{w} P_{8}(t)+\gamma_{x_{1}} P_{3}(t) \\
P_{2}^{\prime}(t)+\left(\eta_{u}+\eta_{w}+\eta_{x_{2}}+\eta_{v_{1}}+\gamma_{x_{1}}\right) P_{2}(t)= \\
\eta_{x_{1}} P_{0}(t)+\gamma_{u} P_{9}(t)+\gamma_{w} P_{10}(t) \\
+\gamma_{x_{2}} P_{11}(t)+\gamma_{v_{1}} P_{3}(t) \\
P_{3}^{\prime}(t)+\left(\eta_{u}+\eta_{w}+\eta_{x_{2}}+\eta_{v_{2}}+\gamma_{x_{1}}+\gamma_{v_{1}}\right) P_{3}(t)= \\
\eta_{x_{1}} P_{1}(t)+\eta_{v_{1}} P_{2}(t)+\gamma_{x_{2}} P_{12}(t) \\
+\gamma_{u} P_{13}(t)+\gamma_{v_{2}} P_{14}(t)+\gamma_{w} P_{15}(t)
\end{gathered}
$$

$$
P_{i}^{\prime}(t)+\gamma_{j} P_{i}(t)=\mu_{j} P_{k}(t)
$$

Where,

$i=4,5, j=u$, w when $k=0$

$i=6,7,8, j=u, v_{2}, w$ when $k=1$

$i=9,10,11, j=u, w, x_{2}$ when $k=2$

$i=12,13,14,15, j=u, v_{2}, w, x_{2}$ when $k=3$

With initial conditions at $t=0$,

$$
P_{i}(t)=\left\{\begin{array}{l}
1, \text { for } i=0, \\
0, \text { Otherwise }
\end{array}\right.
$$

Equation 1-6 are simplified using matrix method and C programming.

Since ' 16 ' is the number of all the possible transition states of the complex structure. So, the system of differential equations can be written for the above equations as:

$$
(\theta I-Q) \bar{P}_{i}(t)=O
$$

Where $\theta=d / d t$, $O$ is the null matrix, $Q$ is the matrix of $P_{i}(t)$ coefficients in the equation of differential differences. $\bar{P}_{i}(t)=\left[P_{1}(t) P_{2}(t) P_{3}(t)\right.$. $\left.P_{16}(t)\right]^{T}$ The equations reduce to $P^{-1}(\theta I-E) \bar{P}_{i}(t)=O$, where $P$ is the matrix such that $P^{-1} Q P=E$, and $E=\left(e_{1}, e_{2, \ldots \ldots . . .} e_{n}\right)$ is the matrix of Eigenvalues of the matrix $Q$.

The availability of the system is the sum of the availabilities of working subsystems.

$$
\begin{aligned}
& A v(t)=P_{0}(t)+P_{1}(t)+P_{2}(t)+P_{3}(t) \\
& =1+\left(a_{11}+a_{21}+a_{31}+a_{41}+\ldots\right) t+\left(b_{11}+b_{21}+b_{31}+b_{41}+\ldots .\right) t^{2} / 2 !+\ldots
\end{aligned}
$$

The entries $a_{i j}$, and $b_{i j}$, are respective entries in $Q, R=Q \bar{P}_{i}(0), S=Q R=Q^{2} \bar{P}_{i}(0)$ so on. 


$$
\text { Matrix } Q=\left[\begin{array}{cccccccccccccccc}
-\mathrm{a}_{1} & \gamma_{v_{I}} & \gamma_{\mathrm{x}_{1}} & 0 & \gamma_{\mathrm{u}} & \gamma_{\mathrm{w}} & 0 & 0 & 0 & 0 & 0 & 0 & 0 & 0 & 0 & 0 \\
\eta_{v_{I}} & -\mathrm{a}_{2} & 0 & \gamma_{\mathrm{x}_{1}} & 0 & 0 & \gamma_{\mathrm{u}} & \gamma_{\mathrm{v}_{2}} & \gamma_{\mathrm{w}} & 0 & 0 & 0 & 0 & 0 & 0 & 0 \\
\eta_{\mathrm{x}_{1}} & 0 & -\mathrm{a}_{3} & \gamma_{v_{1}} & 0 & 0 & 0 & 0 & 0 & \gamma_{\mathrm{u}} & \gamma_{\mathrm{w}} & \gamma_{\mathrm{x}_{2}} & 0 & 0 & 0 & 0 \\
0 & \eta_{\mathrm{x}_{1}} & \eta_{v_{1}} & -\mathrm{a}_{4} & 0 & 0 & 0 & 0 & 0 & 0 & 0 & 0 & \gamma_{\mathrm{x}_{2}} & \gamma_{\mathrm{u}} & \gamma_{\mathrm{v}_{2}} & \gamma_{\mathrm{w}} \\
\eta_{u} & 0 & 0 & 0 & -\gamma_{\mathrm{u}} & 0 & 0 & 0 & 0 & 0 & 0 & 0 & 0 & 0 & 0 & 0 \\
\eta_{w} & 0 & 0 & 0 & 0 & -\gamma_{\mathrm{w}} & 0 & 0 & 0 & 0 & 0 & 0 & 0 & 0 & 0 & 0 \\
0 & \eta_{u} & 0 & 0 & 0 & 0 & -\gamma_{\mathrm{u}} & 0 & 0 & 0 & 0 & 0 & 0 & 0 & 0 & 0 \\
0 & \eta_{\mathrm{v}_{2}} & 0 & 0 & 0 & 0 & 0 & -\gamma_{\mathrm{v}_{2}} & 0 & 0 & 0 & 0 & 0 & 0 & 0 & 0 \\
0 & \eta_{w} & 0 & 0 & 0 & 0 & 0 & 0 & -\gamma_{\mathrm{w}} & 0 & 0 & 0 & 0 & 0 & 0 & 0 \\
0 & 0 & \eta_{u} & 0 & 0 & 0 & 0 & 0 & 0 & -\gamma_{\mathrm{u}} & 0 & 0 & 0 & 0 & 0 & 0 \\
0 & 0 & \eta_{w} & 0 & 0 & 0 & 0 & 0 & 0 & 0 & -\gamma_{\mathrm{w}} & 0 & 0 & 0 & 0 & 0 \\
0 & 0 & \eta_{x_{2}} & 0 & 0 & 0 & 0 & 0 & 0 & 0 & 0 & -\gamma_{x_{2}} & 0 & 0 & 0 & 0 \\
0 & 0 & 0 & \eta_{x_{2}} & 0 & 0 & 0 & 0 & 0 & 0 & 0 & 0 & -\gamma_{x_{2}} & 0 & 0 & 0 \\
0 & 0 & 0 & \eta_{u} & 0 & 0 & 0 & 0 & 0 & 0 & 0 & 0 & 0 & -\gamma_{\mathrm{u}} & 0 & 0 \\
0 & 0 & 0 & \eta_{\mathrm{v}_{2}} & 0 & 0 & 0 & 0 & 0 & 0 & 0 & 0 & 0 & 0 & -\gamma_{\mathrm{v}_{2}} & 0 \\
0 & 0 & 0 & \eta_{w} & 0 & 0 & 0 & 0 & 0 & 0 & 0 & 0 & 0 & 0 & 0 & -\gamma_{\mathrm{w}}
\end{array}\right]
$$

Where $\quad a_{1}=\eta_{u}+\eta_{w}+\eta_{x_{I}}+\eta_{v_{I}}$

$$
\begin{aligned}
& a_{2}=\eta_{u}+\eta_{w}+\eta_{x_{I}}++\eta_{v_{2}}+\gamma_{v_{I}} \\
& a_{3}=\eta_{u}+\eta_{w}+\eta_{x_{2}}+\eta_{v_{I}}+\gamma_{x_{I}} \\
& a_{4}=\eta_{u}+\eta_{w}+\eta_{x_{2}}+\eta_{v_{2}}+\gamma_{x_{I}}+\gamma_{v_{I}}
\end{aligned}
$$

\section{RESULTS AND DISCUSSION}

\section{Availability Analysis}

For distinctive values of the failure and repair rates, the availability of the leaf plant is determined. The failure values and rates of repair are taken as constant:

$$
\begin{aligned}
& \eta_{u}=0.002, \eta_{v_{1}}=0.001, \eta_{v_{2}}=0.004, \quad \gamma_{\mathrm{u}}=0.02, \gamma_{\mathrm{v}_{1}}=0.01, \gamma_{\mathrm{v}_{2}}=0.04 \\
& \eta_{w}=0.0025, \eta_{x_{1}}=0.0025, \eta_{x_{2}}=0.005, \gamma_{\mathrm{w}}=0.02, \gamma_{\mathrm{x}_{1}}=0.02, \gamma_{\mathrm{x}_{2}}=0.05
\end{aligned}
$$

Table 1 is shown in the support of the above data. The analog graph is shown in Figure 2.

\section{Numerical Analysis}

With the help of the C program, we calculated the consequence of parameters on the system's availability and display in Table 2 to 7 in the time horizon of 10 months to 50 months. From the Table 1, it has been noticed that as the failure rate rises, the availability of the system reduces. 
Table 1

Availability corresponding to the time

\begin{tabular}{cccc}
\hline Time & Availability & Time & Availability \\
\hline $\mathbf{0}$ & 1 & 40 & $\mathbf{0 . 8 8 0 4 3 3}$ \\
$\mathbf{5}$ & 0.978644 & 45 & $\mathbf{0 . 8 7 1 8 6 5}$ \\
$\mathbf{1 0}$ & 0.959463 & 50 & $\mathbf{0 . 8 6 4 3 3 0}$ \\
$\mathbf{1 5}$ & 0.942279 & 55 & $\mathbf{0 . 8 5 7 8 3 9}$ \\
$\mathbf{2 0}$ & 0.926918 & 60 & $\mathbf{0 . 8 5 2 5 0 0}$ \\
$\mathbf{2 5}$ & 0.913207 & 65 & $\mathbf{0 . 8 4 8 6 2 1}$ \\
$\mathbf{3 0}$ & 0.900986 & 70 & $\mathbf{0 . 8 4 6 8 1 2}$ \\
$\mathbf{3 5}$ & 0.890105 & 75 & $\mathbf{0 . 8 4 8 1 6 1}$ \\
\hline
\end{tabular}

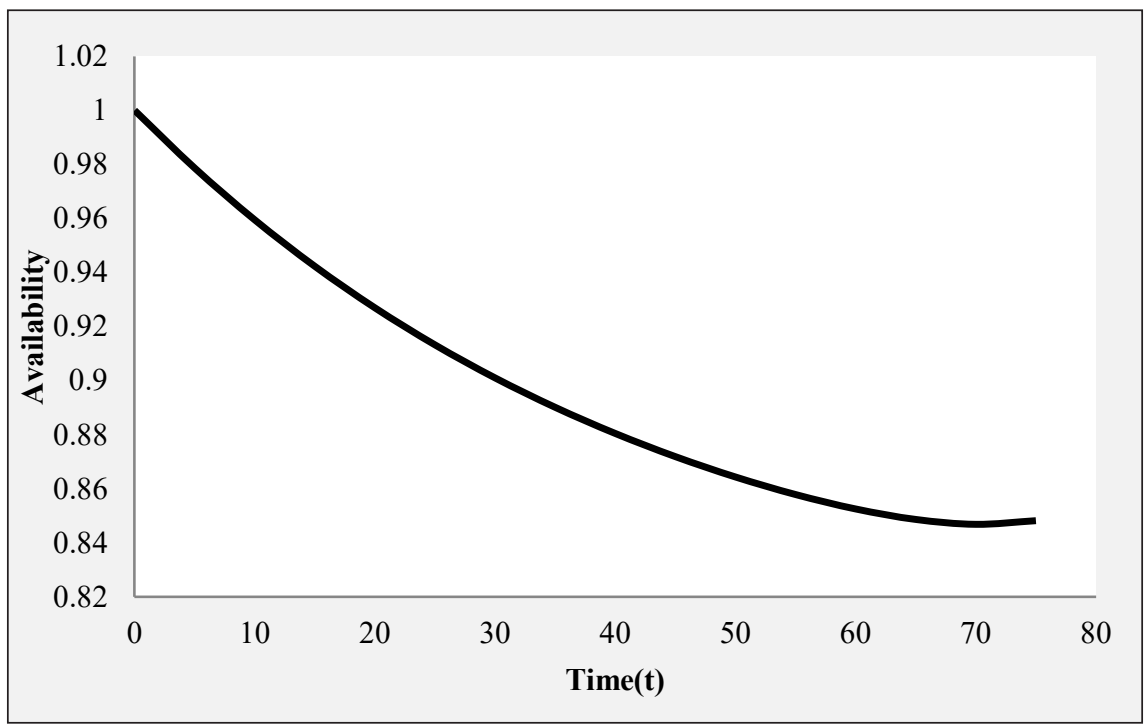

Figure 2. Time-dependent availability graph

Table 2

Impact of the shearing component failure rate on system availability

\begin{tabular}{ccccc}
\hline Months $/ \eta_{u}$ & 0.002 & 0.004 & 0.006 & 0.008 \\
\hline 10 & 0.95946 & 0.94228 & 0.92543 & 0.90891 \\
20 & 0.92691 & 0.89723 & 0.86863 & 0.84107 \\
30 & 0.90098 & 0.86225 & 0.82554 & 0.70733 \\
40 & 0.88043 & 0.83521 & 0.79298 & 0.75352 \\
50 & 0.86433 & 0.81456 & 0.76873 & 0.72653 \\
\hline
\end{tabular}


Table 3

Impact of the first punching component failure rate on system availability

\begin{tabular}{ccccc}
\hline Months $/ \eta_{v_{1}}$ & 0.001 & 0.002 & 0.003 & 0.004 \\
\hline 10 & 0.95946 & 0.95930 & 0.95914 & 0.95898 \\
20 & 0.92691 & 0.92639 & 0.92588 & 0.92538 \\
30 & 0.90098 & 0.90001 & 0.89906 & 0.89813 \\
40 & 0.88043 & 0.87898 & 0.87758 & 0.87621 \\
50 & 0.86433 & 0.86244 & 0.86063 & 0.85890 \\
\hline
\end{tabular}

Table 4

Impact of the second punching component failure rate on system availability

\begin{tabular}{ccccc}
\hline Months $/ \eta_{v_{2}}$ & 0.004 & 0.005 & 0.006 & 0.007 \\
\hline 10 & 0.95946 & 0.95942 & 0.95938 & 0.95934 \\
20 & 0.92691 & 0.92679 & 0.92666 & 0.92654 \\
30 & 0.90098 & 0.90075 & 0.90052 & 0.90030 \\
40 & 0.88043 & 0.88009 & 0.87976 & 0.87943 \\
50 & 0.86433 & 0.86389 & 0.86347 & 0.86306 \\
\hline
\end{tabular}

Table 5

Impact of the heating component failure rate on system availability

\begin{tabular}{ccccc}
\hline Months $/ \eta_{w}$ & 0.0025 & 0.0035 & 0.0045 & 0.0055 \\
\hline 10 & 0.95946 & 0.95083 & 0.94228 & 0.93382 \\
20 & 0.92691 & 0.91193 & 0.89723 & 0.88279 \\
30 & 0.90098 & 0.88136 & 0.86225 & 0.84365 \\
40 & 0.88043 & 0.85743 & 0.83521 & 0.81373 \\
50 & 0.86433 & 0.83893 & 0.81456 & 0.79117 \\
\hline
\end{tabular}

Table 6

Impact of the first assembling component failure rate on system availability

\begin{tabular}{ccccc}
\hline Months $/ \eta_{x_{1}}$ & 0.0025 & 0.0035 & 0.0045 & 0.0055 \\
\hline 10 & 0.95946 & 0.95927 & 0.95909 & 0.95891 \\
20 & 0.92691 & 0.92636 & 0.92582 & 0.92528 \\
30 & 0.90098 & 0.90003 & 0.89910 & 0.89819 \\
40 & 0.88043 & 0.87912 & 0.87785 & 0.87662 \\
50 & 0.86433 & 0.86280 & 0.86133 & 0.85993 \\
\hline
\end{tabular}


Table 7

Impact of the second assembling component failure rate on system availability

\begin{tabular}{ccccc}
\hline Months $/ \eta_{x_{2}}$ & 0.005 & 0.006 & 0.007 & 0.008 \\
\hline 10 & 0.95946 & 0.95937 & 0.95928 & 0.95916 \\
20 & 0.92691 & 0.92664 & 0.92637 & 0.92610 \\
30 & 0.90098 & 0.90051 & 0.90005 & 0.89960 \\
40 & 0.88043 & 0.87979 & 0.87916 & 0.87854 \\
50 & 0.86433 & 0.86359 & 0.86288 & 0.86219 \\
\hline
\end{tabular}

The result shown in Table 2 reveals the impact of the shearing component on the system's availability. By differing the failure rate from 0.002 to 0.008 and fixing other parameters, around $24.27 \%$ reduces the availability of the leaf plant in the time from 10 months to 50 months. Table 3 demonstrates the effect of $\eta_{v_{1}}$ which decreases the availability about $10.48 \%$ at the same time while varying the failure rate from 0.001 to 0.004 . Similarly, Table 4 shows that as the failure rate of $\eta_{\mathrm{v}_{2}}$ increases from 0.004 to 0.007 , the availability also decreases $10.04 \%$ of the leaf plant. Table 5 presents the system's availability of heating component. By varying the failure rate from 0.0025 to 0.0055 and fixing other parameters around $17.53 \%$ reduces the availability. Table 6 and 7 reveals the impact of $\eta_{x_{1}}$ and $\eta_{x_{2}}$ on the system's availability, around $10.37 \%$ and $10.13 \%$ reduces the availability of the leaf plant in the time from 10 months to 50 months. By differing the failure rate from 0.0025 to 0.0055 and 0.005 to 0.008 , respectively.

\section{CONCLUSIONS}

The target of this paper is to recognize the critical points of the system so that appropriate maintenance strategies can be applied. The approach proposed is simple to use with a large number of differential equations in the complex system and helps to measure the availability of the leaf spring manufacturing plant. The variation in availability concerning time is shown in Table 1 and Figure 2. Availability initially gradually decreases with respect to time and becomes almost steady after a long period of time. From Table 2 to 7 , we can easily study the effects of failure rates of different subsystems on the availability of the complete system. A comparative report from Table 1 to 7 shows that the shearing component should pay more attention to improve the availability of the system because it influences the availability of the entire system than any other. The heating component also has a minor influence on system availability. The other subsystems almost have the same effect on the performance of the system. Such findings are extremely useful in enhancing the efficiency of the system by implementing effective maintenance policies. 


\section{ACKNOWLEDGEMENT}

The reviewers were extremely helpful in improving the article, which the authors greatly appreciate.

\section{REFERENCES}

Agarwal, S. C., \& Bansal, S. (2009). Reliability analysis of a standby redundant complex system with changing environment under head of line repair discipline. Bulletin of pure and applied sciences, 28(1), 165-173.

Aggarwal, A. K., Kumar, S., Singh, V., \& Garg, T. K. (2015). Markov modeling and reliability analysis of urea synthesis system of a fertilizer plant. Journal of Industrial Engineering International, 11, 1-14. https:// doi:10.1007/s40092-014-0091-5

Bansal, S., \& Tyagi, S. (2018). Reliability analysis of screw manufacturing plant using orthogonal matrix method. Pertanika Journal of Science \& Technology, 26(4), 1789-1800.

Garg, S., Singh, J., \& Singh, D. V. (2010). Availability and maintenance scheduling of a repairable block-board manufacturing system. International Journal of Reliability and Safety, 4(1), 104-118. https://doi:10.1504/ IJRS.2010.029567

Gupta, R., Ekata, \& Batra, C. M. (2019). Estimate reliability parameters in bio fuel plant using neural network architecture. International Journal of Innovative Technology and Exploring Engineering (IJITEE), 8(11), 440-445. https://doi: 10.35940/ijitee.K1392.0981119

Jain, M., Kumar, R. M., \& Kumar, P. (2020). Maintainability of redundant machining system with vacation, imperfect recovery and reboot delay. Arabian Journal for Science and Engineering, 45, 2145-2161. https://doi.org/10.1007/s13369-019-04060-w

Jain, M., Sharma, G. C., \& Baghel, K. P. S. (2004). N policy for M/G/1 machine repair model with mixed standby components, degraded failure and Bernoulli feedback. International Journal of Engineering, $17(3), 279-288$.

Kumar, D., Singh J., \& Pandey, P. C. (1989). Availability of a washing system in the paper industry. Microelectronics Reliability, 29(5), 775-778. https://doi:10.1016/0026-2714(89)90177-7

Kumar, R., \& Kadyan, M. S. (2018). Reliability modelling and study of failure mechanism of distillery plant using supplementary variable technique. Life Cycle Reliability and Safety Engineering ,7, 137-146. https:// doi.org/10.1007/s41872-018-0053-9

Kumar, S., \& Reddy, B. C. (2017). Modelling and structural analysis of leaf spring using finite element method. International Research Journal of Engineering and Technology, 4(12),1155-1161.

Mangey, R., \& Manglik, M. (2016). An analysis to multi-state manufacturing system with common cause failure and waiting repair strategy. Cogent Engineering, 3, 1-20. https://doi.org/10.1080/23311916.2016.1266185

Mehta, M., Singh, J., \& Singh, M. (2017). Reliability and availability evaluation of a series-parallel system subject to random failure. Indian Journal of Science and Technology, 10(31), 1-11. https://doi: 10.17485/ ijst/2017/v10i31/116145 
Shakuntla, S., Lal, A. K., Bhatia, S. S., \& Singh, J. (2011). Reliability analysis of polytube industry using supplementary variable technique. Applied Mathematics and Computation, 218(8), 3981-3992. https:// doi:org/10.1016/j.amc.2011.10.016

Singh, J., \& Mahajan, P. (1999). Reliability of utensils manufacturing plant - A case study. Opsearch, 36(3), 260-269. https://doi.org/10.1007/BF03398580

Venkatesan, M., \& Devaraj, H. D. (2012). Design and analysis of composite leaf spring in light vehicle. International Journal of Modern Engineering Research, 2(1), 213-218.

Yadav, O P., Choudhary, N., \& Bilen, N. (2008). Complex system reliability estimation methodology in the absence of failure data. Quality and Reliability Engineering International, 24, 745-764. https://doi. org/10.1002/qre.920 
